\title{
Understanding the contribution of tunnels to the overall energy consumption of and carbon emissions from a railway
}

\author{
James A. Pritchard ${ }^{1}$, John Preston ${ }^{1}$ \\ ${ }^{a}$ Transportation Research Group, University of Southampton, Boldrewood Campus, Building \\ 176, Southampton SO16 7QF, United Kingdom
}

\begin{abstract}
Tunnels can contribute significantly to the overall energy consumption and carbon emissions of a railway, both in terms of embodied energy and emissions (those associated with the materials and the construction process) and in terms of operational energy and emissions (due to the increased air resistance experienced by a train inside a tunnel). Although tunnels may be a necessary component of railway infrastructure, it is important that their impact on carbon emissions is fully understood, especially when comparing the railway with other modes. This paper reviews existing literature and uses a case study to develop understanding. Trade-offs between embodied and operational energy and emissions are explored. Keywords: Tunnels; Carbon; Energy; Rail
\end{abstract}

\section{Introduction}

Tunnels are an important component of railway infrastructure. In Europe, about $10 \%$ of conventional and high-speed railway lines are in tunnels (Network Rail, 2009, Table 3.3), whilst the figure for some suburban networks is much 5 higher. For example, $45 \%$ of the London Underground network is in tunnels (Transport for London, 2015).

The requirements of the vertical alignment of railway lines in undulating ground often mean that tunnels are necessary (HS2 Ltd, 2013), whilst they may also be desirable for other reasons, such as the avoidance of surface-level

Preprint submitted to Transportation Research Part D

September 7, 2018 
disruption in an urban area. In terms of sustainability, tunnels could help avoid social and economic concerns arising from the bisection of urban communities or rural farmland, and environmental concerns surrounding noise and visual intrusion. However, tunnels also raise potential sustainability concerns of their own, especially regarding energy consumption and carbon dioxide $\left(\mathrm{CO}_{2}\right)$ emissions.

The energy consumption and embodied $\mathrm{CO}_{2}$ emissions associated with tunnel construction appear to be disproportionately high; Network Rail (2009, Table 2.10) suggest that the greenhouse gas (GHG) emissions (in terms of carbon dioxide equivalent $\left.\left(\mathrm{CO}_{2} \mathrm{e}\right)\right)$ from sections in tunnels are between four and five times higher per route-km than the open sections. Workman and Soga (2004) estimated that the embodied emissions associated with the construction of just $7.5 \mathrm{~km}$ of twin-bore tunnels for the Channel Tunnel Rail Link (CTRL) in the UK accounted for $2.1 \%$ of all emissions associated with the UK construction industry in 1999. A key reason for this is that tunnel construction utilises equipment which consumes a lot of energy (Ahn et al., 2010). Operationally, the air resistance experienced by a train running through a tunnel is higher than that experienced by a train on open track, and the resulting increase in energy consumption can be assumed to lead to a similar increase in $\mathrm{CO}_{2}$ emissions, depending on how the train is powered and how clean the electricity grid is assumed to be.

Developing a proper understanding of the energy consumption and $\mathrm{CO}_{2}$ emissions associated with the construction and operation of railway tunnels is important, for a number of reasons. Firstly, although energy-efficiency may be seen as a relative strength of rail compared with other modes (Armstrong and Preston, 2010), it is clear that tunnels can have a potentially significant impact.

35 Modal comparisons used to inform future transport policies must adequately take tunnels into account if reducing energy consumption and $\mathrm{CO}_{2}$ emissions are important goals. Secondly, not all rail tunnels are necessary, and it is important that designers of railway infrastructure are properly informed when weighing up the merits (sustainability-related and otherwise) of including a 40 tunnel. Finally, it is thought that the design of a tunnel can affect the relative 
sizes of the embodied and operational energy consumption and $\mathrm{CO}_{2}$ emissions, and that there may therefore be an optimum design for minimising overall energy consumption and emissions.

Building on previous work (Pritchard, 2015), this paper begins by exploring the embodied energy and $\mathrm{CO}_{2}$ emissions associated with railway tunnels, before going on to consider operational energy consumption and emissions; in both cases, relevant literature is reviewed where appropriate, and data from part of the new "Crossrail" underground railway in London are considered. Whereas existing studies found in the literature tend to focus solely on either the embodied or the operational emissions, these data for Crossrail are valuable because they cover the embodied emissions and operational emissions of the same system, allowing the overall impact to be considered. Finally, some general calculations are undertaken to demonstrate the way in which the size of the tunnel diameter may change the overall energy consumption and emissions.

\section{Embodied energy and emissions}

Workman and Soga (2004) define the embodied energy of an item in simple terms as "the total energy that can be attributed to bringing that item to its existing state." A parallel definition could be used for embodied $\mathrm{CO}_{2}$ emissions, noting that there is typically a direct link between energy consumed and $\mathrm{CO}_{2}$ emissions (such emissions may occur directly on site or indirectly as a result of electricity generation). Embodied energy and emissions in infrastructure should take in to account both the materials used and the processes involved in construction. The embodied energy and emissions of the materials should include raw material extraction, refining, processing and manufacturing processes, and the transportation of the materials, both between processes and to the construction site. Quantifying these things is not straightforward, and the data are subject to uncertainty and variation. A key reason for this is that the boundaries are often blurred - for example, when considering the transportation of materials, it could be argued that a suitable proportion of the overheads of 
the transportation company used should also be included in the calculations, in addition to the direct energy and emissions arising from moving goods between two points. The problem with such diligence is that obtaining detailed data can be hard, and the calculations can be dependent on individual interpretation. There does not appear to be a consistent standard for determining boundaries, 75 and different data sources may be based on different assumptions. Allwood et al. (2012, p.20) note that "the materials producing industries are highly sensitive to the presentation of energy and emissions data and ... only report the most positive story."

Materials aside, the embodied energy and emissions of the construction processes are mainly attributable to the vehicles and machinery used, but may also include other factors, such as the transport of personnel to and from the construction site. Workman and Soga (2004) additionally suggest that embodied energy and emissions should also include appropriate proportions of the energy and emissions associated with the vehicles and machinery used, and should take in to account the construction and maintenance of associated buildings and roads.

After introducing embodied energy and emissions in a little more detail, this section includes discussions on choosing an appropriate metric for presenting the data, and on accounting for the life span of infrastructure. A single figure for 90 each of the embodied energy and emissions can be calculated, representing the total energy expended by and $\mathrm{CO}_{2}$ emissions from the infrastructure construction. Although this can be valuable, disadvantages of presenting the data in this format include the fact that it may not be easy to make meaningful comparisons with other infrastructure projects or with other aspects of the railway. This is because total figures do not take into account the lifespan of the infrastructure or the usage of the system. For the same reason, it can also be difficult to include the embodied energy and emissions of maintenance activities.

Data from existing studies are then presented, beginning with some work on new high-speed railway lines, illustrating the significance of railway tunnels compared with the rest of the infrastructure. 


\subsection{Embodied energy and emissions in the materials themselves}

Data are available for the embodied carbon and energy in construction materials, for example in a database compiled at the University of Bath (Hammond and Jones, 2011). This means that it is theoretically possible to estimate the Machine (TBM) may be designed and built for a single project). Some details of construction techniques, plant and labour hours have been documented, and could be expected to vary little from project to project; for example, some details for the different types of track are given in a report by Dunne and Ceney 130 (2005), and some work has been done to gather data for some standard types of 
machinery. On the other hand, some aspects of a project will be more variable, such as the landscaping required at a particular location and the transport distances of materials to and waste from the construction site.

\subsection{Choosing a metric for the embodied energy and emissions of railway infrastructure}

As implied by the definition given by Workman and Soga (2004), embodied energy and emissions are often presented in absolute terms. Although such data are valuable, they have limitations. For example, by only considering the current state of the infrastructure, ongoing costs, such as maintenance, are typically excluded. Similarly, if a component has a relatively long life-expectancy and doesn't need replacing regularly, relatively high embodied energy and emissions may become less of a concern over time.

When comparing different modes of transport, it is also generally preferable to use a metric which considers the utilisation of the system (in terms of passengers or freight). For this reason, Chester and Horvath (2009) present their findings in terms of passenger-km, enabling direct comparisons to be made with operational aspects of the systems considered. In other literature reviewed, embodied carbon and energy are typically given per distance per year. This is harder to compare directly with the energy and emissions of the operational aspects of a railway, but doesn't require any knowledge of expected passenger usage. In both cases, however, the expected lifespan of the infrastructure must be known.

In order to present the data on a per-passenger basis, the total number of passenger-km travelled over the infrastructure during its lifetime must be estimated. This means that some knowledge of passenger occupancy levels (the load factor) must be known, and — as with any public transport system — this can vary considerably, both between different services and throughout a given service as stops are made. The impact of load factor on emissions calculations was considered in-depth in earlier work (Pritchard, 2015). In their work, Chester and Horvath (2009) assumed that the load factor of trains varied from $25 \%$ of the number of seats up to $110 \%$ (to allow for standing passengers). In 2005/6, 
the average load factor for trains in the UK was found to be about 31\% (RSSB, 2007).

When choosing a metric for GHG emissions, it is also important to note the difference between data given in terms of $\mathrm{CO}_{2}$ and data given in terms of $\mathrm{CO}_{2}$ e. In terms of quantity, $\mathrm{CO}_{2}$ is the main GHG (Department of Energy \& Climate Change, 2012), but it can be desirable to take into account the effects of other GHGs, such as methane $\left(\mathrm{CH}_{4}\right)$ and nitrous oxide $\left(\mathrm{N}_{2} \mathrm{O}\right) \cdot \mathrm{CO}_{2} \mathrm{e}$ is a measurement which includes both $\mathrm{CO}_{2}$ and other GHGs, scaling their different radiative properties and lifetimes in the atmosphere relative to the radiative forcing of $\mathrm{CO}_{2}$. Most of the data in this paper are in terms of $\mathrm{CO}_{2}$ only, but some sources used give data in terms of $\mathrm{CO}_{2} \mathrm{e}$. Because different processes emit different levels of GHGs, there is no standard scaling between the two. The difference is typically small, and in some cases, where $\mathrm{CO}_{2}$ is the sole GHG emitted there will be no difference at all; however it is important to note that emissions may be quantified slightly differently.

\subsection{Infrastructure lifespan and the problem of accounting for existing infrastructure}

The infrastructure lifespan over which embodied energy and emissions should be allocated can be determined by a number of things. For example, some components — including ballast and rails — wear out over time, and eventually need to be replaced. For other components, wear and tear is less of a limiting factor, but the lifespan may instead be determined by the length of time over which it would be reasonable to assume the railway remains in active use. For example, the carbon footprinting undertaken by Ademe et al. (2009) assumes that the high-speed line in question has an "operating and maintenance phase" of 30 years, even though it may be fairer to assume that bridges, tunnels and buildings typically have a lifespan of 100 years (Baron et al., 2011). Table 1 gives the expected lifespans generally used by Baron et al. in their analysis of embodied $\mathrm{CO}_{2}$.

The selection of a lifespan over which embodied energy and emissions can be allocated can have a big impact on the data which are ultimately presented. 
Table 1: Estimates of life-span for infrastructure components assumed by Baron et al. (2011)

Element $\quad$ Modelled lifepan [years]

$\begin{array}{ll}\text { Earthworks } & 100\end{array}$

$\begin{array}{ll}\text { Bridges and viaducts } & 100\end{array}$

$\begin{array}{ll}\text { Tunnels } & 100\end{array}$

$\begin{array}{ll}\text { Trenches } & 100\end{array}$

$\begin{array}{ll}\text { Buildings } & 100\end{array}$

$\begin{array}{ll}\text { Rail } & 30\end{array}$

$\begin{array}{ll}\text { Ballast } & 25\end{array}$

$\begin{array}{lr}\text { Telecoms and signalling equipment } & 50\end{array}$

Baron et al. compared calculations for the construction of particular lines where the lifespan of tunnels and bridges is 100 years with calculations made for the same lines on the assumption that bridges and tunnels only have a 60 year lifespan. The relative size of the embodied energy and emissions in these components means that the effect on the life-cycle calculations for the whole project was significant in each case; reducing the expected lifespan from 100 years to 60 years increased the $\mathrm{CO}_{2}$ per passenger-km by between $36 \%$ (for the TGV S-E Atlantic line) and 53\% (for the Taipei-Kaohsiung line).

There are also questions about how to account for existing infrastructure. It could be argued that when assessing the provision of new transport services over existing infrastructure, the embodied energy and emissions of the infrastructure have already been accounted for and have no bearing on the new services. On the other hand, if existing infrastructure is to be included in calculations, it should not necessarily be assessed by modern standards; Baron et al. note 
standards to assess a tunnel built 20 or 30 years ago could serve to underestimate the impact of the embodied energy and carbon.

\section{Sample embodied emissions data}

Sample embodied emissions data for three railway tunnel projects are included and reviewed here. The first two data sets come from existing studies undertaken on high-speed railway systems. The final data set has been provided by Arup for the purposes of this research, and pertains to Crossrail, a suburban railway system being built in London.

The first high-speed rail tunnels considered here are those along the proposed Californian high-speed rail system California High-Speed Rail (CAHSR), for which Chang and Kendall (2011) have published a life-cycle GHG assessment of infrastructure construction. These are twin-bore tunnels, covering 49 route-km (in total, therefore, $98 \mathrm{~km}$ of tunnels are considered). The analysis undertaken by Chang and Kendall is based on the assumption that the CAHSR tunnels would be similar to the Devil's Slide Tunnels (DST), a road tunnel scheme in California. The construction method for the DST was the New Austrian Tunneling Method (NATM) (ILF Inc. Consultants, 2009). Excavation occurs in stages, with the top half of the opening excavated first (topheading), ahead of the lower half (the bench). Excavation methods include use of traditional construction equipment, specialist tunneling equipment and controlled explosives. Initial support elements, typically including rockbolts and lattice girders, and an initial lining, typically shotcrete (sprayed fiber-reinforced concrete), which are dependent on the encountered rock-type, are then installed. The initial lining is flexible enough to allow the rock to deform in a controlled fashion until an equilibrium is reached, and then a final lining (typically reinforced concrete) is constructed.

The second high-speed rail tunnels considered here are the twin-bore $7.5 \mathrm{~km}$ tunnels known as Contract 220 on the CTRL, the high-speed railway in the UK between London, Kent and the Channel Tunnel. Studies have been undertaken 
to estimate the embodied energy (and by extension, GHG emissions) of this project; the initial work undertaken by Workman and Soga (2004) was followed up by Chau et al. (2009) who compared the embodied energy of this tunnelled section with that of an aerial section further along the route. Unlike the CAHSR tunnels, the Contract 220 tunnels were constructed using TBMs. The front of a TBM comprises a rotating cutting head and a screw conveyor to remove the excavated spoil. At the back of the TBM, mechanical arms erect the tunnel lining, comprising reinforced concrete segments. The tail seal of the TBM supports the soil whilst the lining section is locked together. The TBM pushes itself forward from the completed lining, typically with a section length of $1.5 \mathrm{~m}$ (Workman and Soga, 2004). Typically, the concrete segments which make up the lining are manufactured in a purpose-built factory near to the launch point of the TBM.

Finally, data for five twin-bore tunnel sections for the Crossrail project in London have been obtained (Vergoulas and Lee, 2010), covering 35 track-km (because the tunnels are twin-bore, the route-km covered is about half this). The tunnels have been bored using TBMs and have a diameter of $6.2 \mathrm{~m}$.

Each project is summarised in Table 2. Table 3 gives the estimated total carbon emissions for each project, on a per route-km (of tunnelled sections) basis. The data are broken down to show the relative importance of each of the embodied carbon in the materials, the material transportation. and the use of machinery during the construction phase.

The potential uncertainty in the data presented in Table 3 should not be overlooked. Even if the quantities of materials are assumed to be accurate (which they may not be), Chau et al. (2009) suggest that the potential uncertainty in their embodied emissions could result in the total being overestimated by more than $50 \%$. Other factors, such as material transport distances, are also likely to lead to significant variation. Emissions from transport only contribute a relatively small proportion of the overall emissions from the CTRL tunnels, but the calculations assume that the spoil only needed to be transported locally for re-use. Chau et al. note that if the spoil had to be moved $150 \mathrm{~km}$ away 
Table 2: Summary data for the railway tunnels considered in this paper

\begin{tabular}{|c|c|c|c|}
\hline Data source & $\begin{array}{r}\text { Chang and } \\
\text { Kendall (2011) }\end{array}$ & $\begin{array}{r}\text { Workman and } \\
\text { Soga }(2004)\end{array}$ & $\begin{array}{r}\text { Vergoulas and Lee } \\
\text { (2010) }\end{array}$ \\
\hline Tunnel location & CAHSR & CTRL & Crossrail \\
\hline $\begin{array}{l}\text { Tunnel length } \\
\text { [route-km] }\end{array}$ & 49 & 7 & 17 \\
\hline $\begin{array}{l}\text { Tunnel diameter } \\
{[\mathrm{m}]}\end{array}$ & 9 & 7.15 & 6.2 \\
\hline Notes & & nels are twin-b & \\
\hline
\end{tabular}

by truck then the embodied energy of the project would increase by $30 \%$. Similarly, it is noted in the report by Vergoulas and Lee (2010) that estimates of waste-related emissions in earlier work were between 87 and $93 \%$ higher, because of assumptions made about the mode of transport; earlier work assumed that all waste would be removed by road, whereas later figures were updated to reflect a logistics strategy which utilises rail and shipping.

Other reasons for potential variation include assumptions about $\mathrm{CO}_{2}$ emissions from electricity consumption. Vergoulas and Lee (2010) used a factor of 0.43 $\mathrm{kg} \mathrm{CO}_{2}$ per $\mathrm{kWh}$ of electricity sourced for construction processes, but this will vary depending on the electricity generation mix (a later figure for the UK generation mix suggests a slightly higher figure of $0.49 \mathrm{~kg} \mathrm{CO}_{2}$ per $\mathrm{kWh}$ of electricity, including transmission losses (Department for Environment Food and Rural Affairs, 2012)).

Knowing very specific details about the project would help to reduce some of the potential variation - for example, the chosen material suppliers might be able 
Table 3: Embodied emissions for three railway tunnel projects

\begin{tabular}{|c|c|c|c|}
\hline & \multicolumn{3}{|c|}{ Embodied $\mathrm{CO}_{2}$ [tonnes per route-km] (as $\%$ of total) } \\
\hline & CAHSR & CTRL & Crossrail \\
\hline Material & $9,859(76)$ & $8,457(60)$ & $15,303(65)$ \\
\hline \multicolumn{4}{|l|}{ production } \\
\hline Material & $2,247(17)$ & $29(0)$ & $1,309(6)$ \\
\hline \multicolumn{4}{|l|}{ transport } \\
\hline Equipment & $911(7)$ & $5,500(39)$ & $7,040(30)$ \\
\hline Total & 13,016 & 13,986 & 23,652 \\
\hline
\end{tabular}

that if the specific transportation, waste, and electricity supply arrangements were better understood it would enable some calculations to be made with more certainty. Some of the necessary data may not be easily obtainable, however, and the process in any case could be time consuming.

285 it is possible to gain some idea from Chang and Kendall (2011) of how the estimations for the embodied GHG emissions of the tunnels compare with the embodied GHG emissions of the rest of the infrastructure. Their data are summarised in Table 4 accordingly, using lifespan data from Table 1 to estimate the embodied emissions on a tonnes per route-km per year basis.

The data in Table 4 can be compared with estimates of embodied $\mathrm{CO}_{2}$ in railway infrastructure given by Baron et al. (2011), given in Table 5.

It is noted that the data given for the Californian tunnels in Table 4 is less than the range suggested in Table 5, and a number of reasons are suggested for 295 this. Firstly, the tunnel construction methods are different - the data for the CAHSR assume that the NATM is used, whereas the other tunnels considered 
Table 4: A breakdown of the embodied $\mathrm{CO}_{2} \mathrm{e}$ emissions of CAHSR

\begin{tabular}{|c|c|c|c|c|}
\hline & $\begin{array}{r}\text { Length of } \\
\text { Section }[\mathrm{km}]\end{array}$ & $\begin{array}{r}\mathrm{CO}_{2} \mathrm{e} \\
\text { emissions }[\mathrm{t} \\
\text { per route-km] }\end{array}$ & $\begin{array}{r}\text { Assumed } \\
\text { Lifespan } \\
\text { [years] }\end{array}$ & $\begin{array}{r}\mathrm{CO}_{2} \mathrm{e} \\
\text { emissions }[\mathrm{t} \\
\text { per route-km } \\
\text { per year] }(\% \\
\text { of total })\end{array}$ \\
\hline Track & 725 & 1,199 & 25 & $48(15)$ \\
\hline Tunnel & 49 & 13,016 & 100 & $130(42)$ \\
\hline Bridges and & 61 & 12,982 & 100 & $130(41)$ \\
\hline \multicolumn{5}{|l|}{ Viaducts } \\
\hline Electrification & 725 & 96 & 50 & $2(1)$ \\
\hline Earthworks & 138 & 309 & 100 & $3(1)$ \\
\hline
\end{tabular}

are bored using a TBM. This is reflected in Table 3, which shows that the emissions due to the construction equipment are estimated to be much lower for the CAHSR. Secondly, tunnel construction is heavily dependent on a number of factors, including the geological conditions, and the removal of the excavated material (both in terms of method of removal and distance transported), and large variations between projects are not unexpected. Finally, as noted in Section 2.1, there are a number of uncertainties in some of the underlying data, and the data presented in Table 4 and Table 5 are dependent on the sources used and the assumptions made.

Although the embodied emissions data presented here are subject to a number of uncertainties, it is clear from the range of projects considered that tunnels contribute particularly significantly to the embodied energy and emissions of railway infrastructure. For this reason, the total embodied energy and emissions

of a new railway line are heavily dependent on the amount of tunnels and other 
civil engineering infrastructure, as can be seen in comparisons made by Baron et al. (2011), which show that the embodied emissions are more than twice as much per km per year for the high-speed line between Taipei and Kaohsiung as they are for the LGV Mediterrean high-speed line in France. of railway infrastructure, and should not be ignored for that reason alone, Section 4 goes on to consider the impact they have on operational energy and emissions.

\section{Operational energy and emissions} potential effects of tunnels are discussed, and existing work published by HS2 Ltd (2009) is reviewed. Finally, the results of some new simulations, used to model trains in the Crossrail tunnels introduced in Section 2, are presented.

\subsection{The Davis Formula}

Although it is possible to calculate the resistance to motion of trains on the basis of the fundamental laws of physics (considering rolling friction, sliding friction and aerodynamics), such a scientific approach is rarely taken. The process is complex, requiring knowledge of very many parameters and does not 
necessarily lead to useable train resistance data (Rochard and Schmid, 2000). However, the resistance force, $\mathrm{R}$, can be approximated by the Davis Formula an empirical quadratic function of the trains velocity $\mathrm{v}$, written as

$$
R=A+B v+C v^{2}
$$

If $\mathrm{R}$ is in Newtons $(\mathrm{N})$ and $\mathrm{v}$ is in metres per second $\left(\mathrm{ms}^{-1}\right)$, then the coefficients $\mathrm{A}, \mathrm{B}$ and $\mathrm{C}$ have units $\mathrm{N}, \mathrm{Nsm}^{-1}$ and $\mathrm{Ns}^{2} \mathrm{~m}^{-2}$ respectively, although in this paper the values are scaled for velocities in terms of $\mathrm{km} / \mathrm{h}$. A and $\mathrm{B}$ include the mechanical resistances (and are mass related), whilst the third term accounts for the aerodynamic resistance (Rochard and Schmid, 2000). Numerous methods are available for calculating these coefficients (RSSB, 2010b); these may include full-scale empirical testing, results from a wind-tunnel (full-scale or otherwise) or use of other empirical relationships. For example, Armstrong and Swift (cited by Rochard and Schmid, 2000), created empirical relationships to calculate the Davis coefficients for a British Rail Electric Multiple Unit (EMU). These are used to estimate A, B and C from other known measurements of the train, including the total mass of the power cars, the total mass of the trailer cars, a drag coefficient, the length and cross-sectional area and the intervehicle gap.

Sample values for the Davis coefficients for three different types of train are given in Table 6. The standard coefficients for the Suburban and Intercity trains are taken from RSSB (2010b) and are based on the UK Class 357 Electrostar (RSSB Train A) and the Pendolino (RSSB Train D) respectively. The values for the High-Speed train are taken from those attributed to the AGV-11 (SYSTRA, 2011).

It is noted that, depending on the cross-sectional area of the tunnel relative to the train, the aerodynamic resistance encountered may be double that experienced in the open (Rochard and Schmid, 2000). This is corroborated by a report by RSSB (2010a), which suggests that the increased aerodynamic resistance in a tunnel can be modeled by using a new value for $\mathrm{C}$ in the Davis equation, 
typically between 1.5 and 2 times the standard value.

The resistance curves for each of the trains in Table 6 were generated using the Davis Equation (Eq. (1)) and are plotted in Fig. 1. Fig. 1 also shows how the resistance curves might be expected to change if the train were in a tunnel (modelled by doubling the Davis $\mathrm{C}$ coefficient in each case).

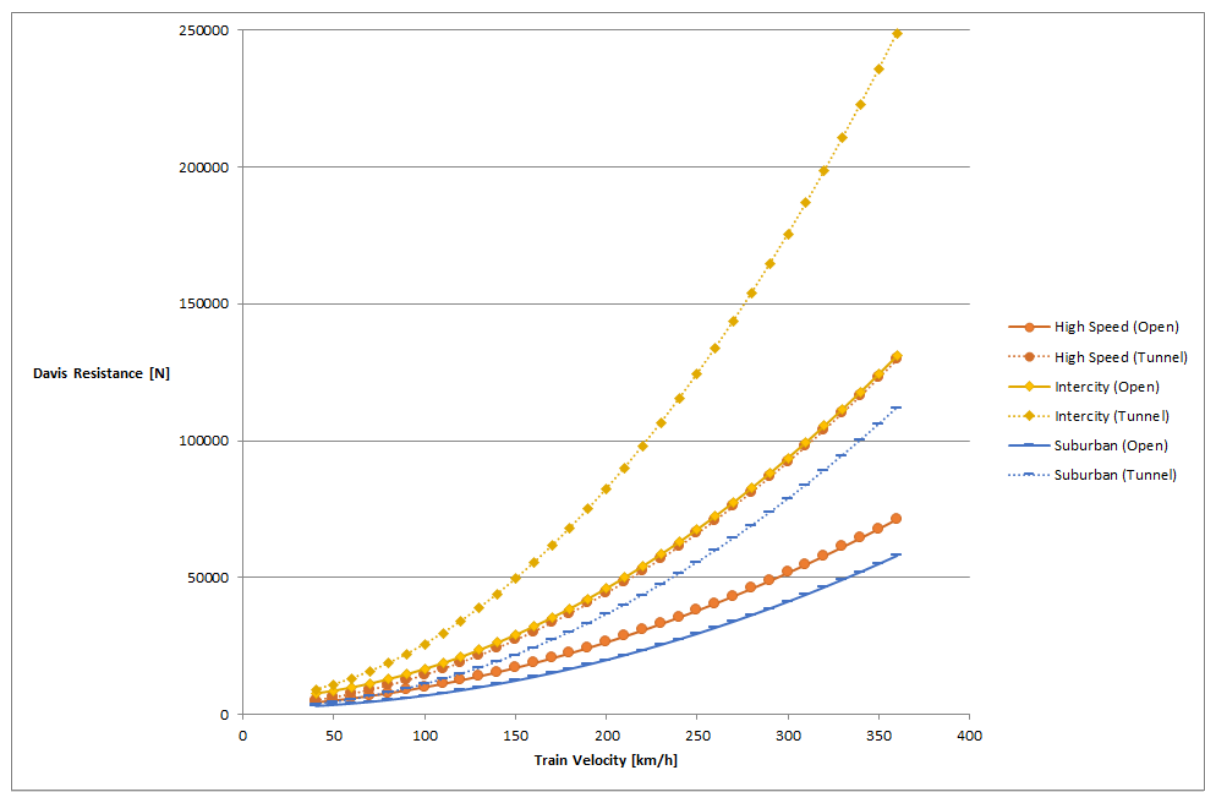

Figure 1: Davis Resistance curves for three types of train

It is well documented - for example by RSSB (2010b) and by Raghunathan et al. (2002) - that the value of $\mathrm{C}$ is proportional to both the length of the train and the head and tail drag coefficients. It is therefore likely that train length is a key reason for the fact that the High Speed and Intercity trains (comprising 10 and 9 vehicles respectively) experience a greater resistance force than the Suburban train (comprising just 4 vehicles). The fact that the High-Speed train experiences less resistance than the Intercity train may well be down to reduced head and tail drag coefficients. In any case, it can be seen that the effect of the tunnel is pronounced, especially at higher speeds. The impact on energy consumption is further modelled in Section 5. 


\subsection{Other resistance forces}

The Davis Formula (Eq. (1)) only covers inertia and running resistance. Other forces include grade resistance (the additional force required to overcome

gradient) and curve resistance (the added resistance experienced by a train operating through a horizontal curve) (AREMA, 2003). Curve resistance and grade resistance can be neglected if the additional assumption is made that the track is straight and level. In any case, the presence of a tunnel is not expected to affect these forces significantly.

\subsection{Work done and energy consumption}

The work done by a moving train can be calculated by multiplying the applied force by the distance moved. The work done, $E$, by the train exerting tractive effort $T$ over a distance $d$ is thus estimated by:

$$
E=T d
$$

If $T$ is given in Newtons ( $\mathrm{N})$ and $d$ is given in meters $(\mathrm{m})$ then this gives work done in terms of joules $(\mathrm{J})$. One kilowatt-hour $(\mathrm{kWh})$ is 3.6 megajoules (MJ). The assumption is that $T$ is constant over the given distance; which is reasonable if $\mathrm{d}$ is chosen to be small enough or the velocity and resistance forces both remain constant. On this basis, the work done over a whole route can be estimated by dividing the route into appropriate segments and summing the work done for each one.

If the train is coasting or braking, then no tractive effort is applied. $T$ and therefore $E$ (the work done) are both zero. Hence:

$$
E=0
$$

If the train is cruising at a constant speed, then the applied tractive effort $T$ must be of equal magnitude to the total resistance forces $R$ experienced by the train. Hence:

$$
E=|R| d
$$


If the train is accelerating (the rate of acceleration $a$ is greater than zero), then according to Newton's second law:

$$
T=m a
$$

Hence:

$$
E=\operatorname{mad}
$$

In this case $m$ is the mass of the train, and $R<m a$. If the rate of acceleration

$a$ needs to be determined, further data about the tractive performance of the specific train need to be obtained.

The actual energy required to move the train will be greater, due to the fact that the traction and transmission systems are not $100 \%$ efficient. This is because there are losses throughout the powertrain (including the alternator, rectifier, motors and gearboxes). The efficiency is expected to vary between different types of train, but in one example, RSSB (2007, p.23) assume that the efficiency of the traction system is $85 \%$. This does not include the efficiency of the internal combustion engine in diesel-powered trains.

\section{Simulating the effects of tunnels on operational energy consumption and emissions}

\subsection{High-speed trains in tunnels}

HS2 Ltd (2009) modelled the impact on energy consumption of a high-speed train running through a tunnel. They modelled a 200m long AGV running at a constant $320 \mathrm{~km} / \mathrm{h}$ through a $10 \mathrm{~km}$ tunnel, and their results, for different diameters of tunnel, are shown in Table 7 . 
Table 5: A summary of the estimated embodied $\mathrm{CO}_{2}$ emissions in a high-speed railway line (Data source: Baron et al., 2011)

\begin{tabular}{|c|c|c|}
\hline Aspect & $\begin{array}{r}\text { Estimated } \mathrm{CO}_{2} \text { emissions } \\
{[\mathrm{t} / \mathrm{km} / \text { year }]}\end{array}$ & Notes \\
\hline Conception Phase & 0.45 & $\begin{array}{l}\text { Includes office works for } \\
\text { planning a high speed } \\
\text { line prior to construction. } \\
\text { Based on data for the } \\
\text { LGV Mediterranee line }\end{array}$ \\
\hline Earthworks & 5 to 22 & $\begin{array}{l}\text { Estimates based on } \\
\text { different TGV lines }\end{array}$ \\
\hline Track & 22.8 (ballasted track) & $\begin{array}{l}\text { The biggest source of } \\
\text { emissions is the steel for } \\
\text { the rails }\end{array}$ \\
\hline Bridges/Viaducts & $\begin{array}{r}31.6 \text { (slab track) } \\
68 \text { (small bridges) to } 183 \\
\text { (large and high viaducts } \\
\text { over valleys) }\end{array}$ & \\
\hline Tunnels & 172 to 243 & \\
\hline Railway Equipment & 3.5 & \\
\hline Stations & 33 to 82 & \\
\hline
\end{tabular}


Table 6: Sample Davis coefficients for different types of train

\begin{tabular}{|c|c|c|c|c|}
\hline \multirow[t]{2}{*}{ Train } & & Suburban & Intercity & High-Speed \\
\hline & $\mathbf{A}$ & 2158 & 5311 & 2500 \\
\hline \multirow{3}{*}{$\begin{array}{l}\text { Davis } \\
\text { Coeffic }\end{array}$} & B & 5.384 & 21.696 & 29 \\
\hline & & & & \\
\hline & $\mathrm{C}$ & 0.4158 & 0.9097 & 0.45 \\
\hline
\end{tabular}


An attempt was made to replicate these results, using the Arup RouteMaster tool (Arup, 2015), which is based on the principles described in Section 4.3. A key aim was to determine the relationship between the tunnel diameter in Table 7 and the multiplication factor of the Davis $\mathrm{C}$ coefficient used to model the impact of the tunnel, but it was discovered that the maximum tractive effort of the AGV is a limiting factor, and there is a point where, actually, the resistance is too high for the train to maintain a speed of $320 \mathrm{~km} / \mathrm{h}$. RouteMaster estimated the energy consumption of the AGV to be $169 \mathrm{kWh}$ for $10 \mathrm{~km}$ at $320 \mathrm{~km} / \mathrm{h}$ in the open air, which is comparable to the HS2 Ltd value in Table 7. Table 8 shows how the energy consumption is modelled to increase with the multiplication factor of the Davis C coefficient (the "Tunnel Factor"); the values in italics are purely theoretical because the resistance forces cannot be overcome by the tractive effort, and maintaining the speed is impossible.

It can be concluded that if the tunnel is as small as $8.5 \mathrm{~m}$ (Table 7), it may not be possible to maintain a running speed of $320 \mathrm{~km} / \mathrm{h}$. Even if it were, it may not be desirable for a number of other reasons; as noted by Raghunathan et al. (2002), aerodynamic concerns also pertain to matters such as passenger comfort (including ear discomfort) and stress upon the train. Table 8 therefore also contains the results for an AGV modelled at the lower speed of $250 \mathrm{~km} / \mathrm{h}$.

44 Because the resistance forces are very heavily speed dependent (Fig. 1), it is noted that the energy saving of lowering the running speed in a tunnel may actually outweigh the costs of the tunnel itself. However, other sustainability concerns, such as the social and economic implications of a reduced running speed, also need to be borne in mind. For example, slower journey times are likely to have commercial implications.

\subsection{Suburban trains in tunnels}

Following the same method in Section 5.1, simulations were carried out for a theoretical suburban train, representative of the type being procured for Crossrail . As well as considering constant speed running, simulations were also conducted for a suburban stopping profile with a uniform stop-spacing of $2 \mathrm{~km}$, 
Table 7: Energy consumption of AGV at $320 \mathrm{~km} / \mathrm{h}$ in $10 \mathrm{~km}$ of tunnels (Data Source: HS2 Ltd, 2009)

\begin{tabular}{rrr} 
Tunnel Diameter $[\mathrm{m}]$ & Work Done $[\mathrm{kWh}]$ & $\begin{array}{r}\text { Increase w.r.t Open } \\
\text { Track }[\mathrm{kWh}](\%)\end{array}$ \\
\hline 8.5 & 167 & $157(94)$ \\
9.8 & 324 & $107(64)$ \\
12 & 274 & $65(39)$ \\
\hline
\end{tabular}

considered to be representative of the Crossrail service in Central London. The results are shown in Table 9 and Table 10 accordingly. When considering the suburban stopping profile, two driving profiles were applied. The first assumed flat-out running, and no coasting. The second allowed for coasting, although this did not apply at higher speeds because the train did not reach cruising speed.

It can be seen that the effects of a tunnel on operational energy consumption (and related emissions) are less pronounced for a suburban train than a high-speed one, which is not surprising given the relationship between resistance forces and speed (Fig. 1). What is noteworthy, however, is that by considering a typical stopping pattern rather than constant speed running, the possible effects are greatly diminished. Table 10 also implies that tunnels have a more significant impact when coasting is part of the driving profile - this makes sense, because if the air resistance is greater, the rate of deceleration during coasting is greater, and this will need to be compensated for in the acceleration and (if applicable) cruising phases. It is important to make clear, though, that the figures in Table 10 are given relative to a baseline for open-air running, and that this baseline is lower when coasting is part of the profile (at $100 \mathrm{~km} / \mathrm{h}$, the work done on an open-air suburban profile is estimated to be in the region of 25.4 
Table 8: Modelled increase in energy consumption of a high-speed AGV in 10km of tunnels

Increase in work done compared with open-air running

\begin{tabular}{|c|c|c|c|}
\hline Tunnel Factor & $\begin{array}{r}\text { Speed: } 320 \mathrm{~km} / \mathrm{h} \\
\text { in both open air } \\
\text { and tunnel }\end{array}$ & $\begin{array}{r}\text { Speed: } 250 \mathrm{~km} / \mathrm{h} \\
\text { in both open air } \\
\text { and tunnel }\end{array}$ & $\begin{array}{r}\text { Speed: } 320 \mathrm{~km} / \mathrm{h} \\
\text { in open air and } \\
250 \mathrm{~km} / \mathrm{h} \text { in } \\
\text { tunnel }\end{array}$ \\
\hline 1.1 & $8 \%$ & $7 \%$ & $-23 \%$ \\
\hline 1.2 & $16 \%$ & $15 \%$ & $-19 \%$ \\
\hline 1.3 & $24 \%$ & $22 \%$ & $-14 \%$ \\
\hline 1.4 & $32 \%$ & $29 \%$ & $-9 \%$ \\
\hline 1.5 & $40 \%$ & $36 \%$ & $-4 \%$ \\
\hline 1.6 & $48 \%$ & $44 \%$ & $1 \%$ \\
\hline 1.7 & $56 \%$ & $51 \%$ & $6 \%$ \\
\hline 1.8 & $64 \%$ & $58 \%$ & $11 \%$ \\
\hline 1.9 & $72 \%$ & $66 \%$ & $16 \%$ \\
\hline 2 & $80 \%$ & $73 \%$ & $20 \%$ \\
\hline 2.1 & $88 \%$ & $80 \%$ & $25 \%$ \\
\hline 2.2 & $96 \%$ & $87 \%$ & $30 \%$ \\
\hline
\end{tabular}


Table 9: Modelled increase in energy consumption of a representative suburban train in $10 \mathrm{~km}$ of tunnels

Increase in work done compared with open-air running

\begin{tabular}{|c|c|c|c|}
\hline Tunnel Factor & $\begin{array}{r}\text { Speed: } 145 \mathrm{~km} / \mathrm{h} \\
\text { in both open air } \\
\text { and tunnel }\end{array}$ & $\begin{array}{r}\text { Speed: } 100 \mathrm{~km} / \mathrm{h} \\
\text { in both open air } \\
\text { and tunnel }\end{array}$ & $\begin{array}{r}\text { Speed: } 145 \mathrm{~km} / \mathrm{h} \\
\text { in open air and } \\
100 \mathrm{~km} / \mathrm{h} \text { in } \\
\text { tunnel }\end{array}$ \\
\hline 1.1 & $6 \%$ & $5 \%$ & $-34 \%$ \\
\hline 1.2 & $13 \%$ & $10 \%$ & $-31 \%$ \\
\hline 1.3 & $19 \%$ & $15 \%$ & $-28 \%$ \\
\hline 1.4 & $26 \%$ & $19 \%$ & $-25 \%$ \\
\hline 1.5 & $32 \%$ & $24 \%$ & $-22 \%$ \\
\hline 1.6 & $38 \%$ & $29 \%$ & $-19 \%$ \\
\hline 1.7 & $45 \%$ & $34 \%$ & $-16 \%$ \\
\hline 1.8 & $51 \%$ & $39 \%$ & $-13 \%$ \\
\hline 1.9 & $57 \%$ & $44 \%$ & $-10 \%$ \\
\hline 2 & $64 \%$ & $49 \%$ & $-7 \%$ \\
\hline 2.1 & $70 \%$ & $53 \%$ & $-4 \%$ \\
\hline 2.2 & $77 \%$ & $58 \%$ & $-1 \%$ \\
\hline
\end{tabular}


Table 10: Modelled increase in energy consumption of a representative suburban train in $10 \mathrm{~km}$ of tunnels

Increase in work done compared with open-air running Suburban Profile; No Coasting Suburban Profile with

Coasting

\begin{tabular}{|c|c|c|c|c|}
\hline Tunnel Factor & $\begin{array}{r}\text { Speed: } 145 \\
\mathrm{~km} / \mathrm{h} \text { in both } \\
\text { open air and } \\
\text { tunnel }\end{array}$ & $\begin{array}{r}\text { Speed: } 100 \\
\mathrm{~km} / \mathrm{h} \text { in both } \\
\text { open air and } \\
\text { tunnel }\end{array}$ & $\begin{array}{r}\text { Speed: } 145 \\
\mathrm{~km} / \mathrm{h} \text { in open } \\
\text { air and } 100 \\
\mathrm{~km} / \mathrm{h} \text { in } \\
\text { tunnel }\end{array}$ & $\begin{array}{r}\text { Speed: } 100 \\
\mathrm{~km} / \mathrm{h} \text { in both } \\
\text { open air and } \\
\text { tunnel }\end{array}$ \\
\hline 1.1 & $0.1 \%$ & $0.6 \%$ & $-20 \%$ & $0.3 \%$ \\
\hline 1.2 & $0.2 \%$ & $1.1 \%$ & $-19 \%$ & $0.7 \%$ \\
\hline 1.3 & $0.4 \%$ & $1.7 \%$ & $-19 \%$ & $1.2 \%$ \\
\hline 1.4 & $0.5 \%$ & $2.2 \%$ & $-18 \%$ & $1.7 \%$ \\
\hline 1.5 & $0.6 \%$ & $2.7 \%$ & $-18 \%$ & $2.2 \%$ \\
\hline 1.6 & $0.8 \%$ & $3.3 \%$ & $-18 \%$ & $2.6 \%$ \\
\hline 1.7 & $1.0 \%$ & $3.8 \%$ & $-17 \%$ & $3.1 \%$ \\
\hline 1.8 & $1.2 \%$ & $4.4 \%$ & $-17 \%$ & $3.6 \%$ \\
\hline 1.9 & $1.5 \%$ & $4.9 \%$ & $-16 \%$ & $4.4 \%$ \\
\hline 2 & $1.9 \%$ & $5.5 \%$ & $-16 \%$ & $4.9 \%$ \\
\hline 2.1 & $2.2 \%$ & $6.0 \%$ & $-15 \%$ & $5.3 \%$ \\
\hline 2.2 & $2.5 \%$ & $6.6 \%$ & $-15 \%$ & $5.6 \%$ \\
\hline
\end{tabular}


$\mathrm{kWh}$ per train $\mathrm{km}$ without coasting, and $23.8 \mathrm{kWh}$ per train $\mathrm{km}$ when coasting is allowed as part of the driving cycle).

Despite the reduced variation of energy consumption and emissions with the size of the tunnel relative to the train (the "Tunnel Factor"), the overall reduction in operational energy consumption and emissions for a wider tunnel relative to the train could be significant over a long period of operation. Section 6 discusses this in more detail.

\section{Investigating the possible trade-offs between embodied and operational emissions}

It was shown in Section 5.1 and Section 5.2 that the effect of tunnels on the operational energy consumption and related emissions of a train is related to the relative size of the tunnel and the train - the wider the tunnel relative to the train, the smaller the "Tunnel Factor" and the lower the increase in energy consumption and emissions. It was also shown in Section 2 that the production and transportation of materials are significant contributors to the embodied energy and emissions, and there is a direct correlation between tunnel size and material quantity (both in terms of that used for the tunnel lining, and waste material excavated). Using the data obtained about the Crossrail project (Vergoulas and Lee, 2010), this section aims to illustrate the possible impacts of boring wider tunnels, and highlights the potential trade-off between operational and embodied energy consumption and emissions.

Table 11 summarises the embodied emissions of the materials used in the Crossrail tunnels, using the estimated totals given by Vergoulas and Lee (2010) and dividing by the number of route-km (taken to be around $17.6 \mathrm{~km}$, with twin-bore tunnels throughout). It is noted that these form around $70 \%$ of the total embodied emissions of the Crossrail tunnels (Table 3). It is thought that the remaining $30 \%$, attributable to the construction processes and operation of the TBMs, will also vary to some extent with tunnel diameter, but insufficient data are available (in part this is due to the fact that the operation of a TBM 
is dominated by other factors, such as the geology of the area, which are often project specific).

Table 11: Embodied emissions of materials used in Crossrail tunnels

Predicted embodied emissions of Crossrail tunnels [t $\mathrm{CO}_{2}$ per route-km]

(Data Source: Vergoulas and Lee, 2010)

Embodied - Materials In

Transport - Materials In

Transport - Waste Materials (not from

TBM)

Transport - Waste Materials via TBM

The input materials are primarily for the tunnel lining, and can therefore be assumed to vary with internal surface area. The waste materials are assumed to vary with internal volume.

For the sake of simplicity, tunnels are in this case assumed to be cylindrical. For such a tunnel of diameter $d$ and length $l$, the internal surface area is described by:

$$
A=\pi d l
$$

Similarly, the internal volume is given by:

$$
A=\pi\left(\frac{d}{2}\right)^{2} l
$$

By scaling the values for Materials In according to Eq. (7), and the values for Materials Out according to Eq. (8), estimates can be made of how the embodied emissions of the Crossrail tunnels might increase should the diameter have been 
increased from $6.2 \mathrm{~m}$. These are summarised in Table 12 . In practice, it is likely that there would have been constraints on the size of the tunnels which could have been bored, including geological constraints and the circumnavigation of existing underground infrastructure, but these are not considered here.

In terms of embodied energy and emissions, there would clearly have been a cost if the Crossrail tunnels were bored to a greater diameter. A key question is whether reduced operational energy consumption and emissions would offset the embodied cost, and be beneficial overall.

Using the values from Table 10, Table 13 gives some indication of the maximum energy saving (in terms of $\mathrm{kWh}$ per train-km) which might be expected for $100 \mathrm{~km} / \mathrm{h}$ suburban operations, if the tunnel width was increased.

Although the potential reduction in $\mathrm{CO}_{2}$ emissions on a per train-km basis seems slight, the overall savings can be significant if the service frequency is high enough. The underground central section of the Crossrail route is expected to have 24 trains per hour (tph) in each direction (48 tph in total) during peak hours (Crossrail Ltd, 2015). Table 14 estimates the annual total reduction in operational $\mathrm{CO}_{2}$ emissions for two scenarios. In the first case, the service frequency is assumed to be 48 tph for 18 hours a day, 364 days a year. This is an unrealistic operating pattern, but serves as an upper bound. In the second 535 case, the service frequency is assumed to be a more realistic 12 tph on average.

If the operating lifespan of a tunnel is assumed to be 100 years (Section 2.4) then the increase in embodied $\mathrm{CO}_{2}$ emissions in terms of tonnes per km per year is estimated to be 13.7 for a $6.7 \mathrm{~m}$ tunnel, rising to 183.5 for a $12.7 \mathrm{~m}$ tunnel. These figures are of the same order of magnitude as those in Table 14, and it is therefore suggested that - in principle - there is an optimum tunnel diameter between $6.7 \mathrm{~m}$ and $12.7 \mathrm{~m}$ which would have resulted in lower overall energy consumption and $\mathrm{CO}_{2}$ emissions. Further work would need to be done to pinpoint the optimum diameter, because the correlation between "Tunnel Factor" and tunnel diameter has not been quantified. The correlation will be 545 specific to a given type of train, and may not be easy to calculate. Furthermore, in any case, it is questionable whether wider Crossrail tunnels would have 
resulted in any net benefits in practice, for several reasons.

The first reason for this is that the operation of the TBMs and other construction equipment was not taken in to account, and it is likely that the total cost of boring wider tunnels would be higher than suggested in Table 12. Furthermore, it may be more desirable to consider an operating lifespan of, for example, 30 years, rather than the total lifespan of the tunnal; in this case, the increase in embodied $\mathrm{CO}_{2}$ emissions in terms of tonnes per km per year would be over 40 for a $6.7 \mathrm{~m}$ tunnel, rising to over 550 for a $12.7 \mathrm{~m}$ tunnel, exceeding the potential reduction in operational emissions over the same time period.

The second reason for this is that the carbon intensity of the electricity grid is expected to decrease in the coming years as more energy comes from cleaner and renewable sources. Table 13 assumed the value of $0.385 \mathrm{~kg} \mathrm{CO}_{2}$ per $\mathrm{kWh}$ of electricity used by Crossrail at the start of operations (Vergoulas and Lee, 2010),

${ }_{50}$ but this is predicted to decrease during the operational lifetime. Vergoulas and Lee (2010) suggest that by 2025 , a value of $0.249 \mathrm{~kg} \mathrm{CO} 2$ per $\mathrm{kWh}$ of electricity might be achieved. In any case, any decrease in the carbon intensity of the grid will lead to a reduction in the estimated savings given in Table 14. Finally, the estimates in Table 13 and Table 14 are based on the target specifications for a Crossrail train over a standardised suburban driving profile, and may not be borne out in reality.

Nonetheless, the findings suggest that there is a potential trade-off not just for intense suburban lines such as Crossrail, but also for high-speed lines, where the lower service frequency is offset by higher savings per train. It is recommended that more detailed calculations are undertaken at the planning stages of future rail projects, in order to ascertain whether changing the diameter of any tunnels can help reduce overall energy consumption and emissions.

\section{Conclusions}

It has been found that tunnels add significantly to both the embodied and operational energy consumption and GHG emissions of railway infrastructure. 
Although the assumptions made and boundary conditions chosen vary across the literature between different projects, it is clear that — in any case the embodied energy and $\mathrm{CO}_{2}$ emissions of a new tunnelled section would be expected to be much higher than for other aspects of railway infrastructure.

The first conclusion of this paper, therefore, is that tunnels must be included when assessing the impact of new railway infrastructure. In the cases where tunnels are not necessary, but desirable for other reasons, it is important to ensure that the increase in energy consumption and embodied emissions are properly quantified, so that an informed decision about the overall benefits can be made. In the cases where tunnels are necessary, it is still important to understand their impact, because they add significantly to the overall figures for the energy consumption and emissions of a railway system - there is a danger that by ignoring them, the potential benefits of new railway infrastructure could be overstated, and comparisons made between other modes could be misleading.

The second conclusion of this paper is that the associated increase in embodied energy and emissions of boring wider tunnels could be offset by a reduction in operational emissions. Further work needs to be done to better quantify the operational energy consumption and emissions in relation to the actual tunnel diameter, and the calculations will depend on the type of train, the type of service and the expected operational lifespan; however, the brief case-study undertaken here for Crossrail suggests that the figures are quite close, such that future railway projects would benefit from more detailed planning in this area. In the case of high-speed lines, the likely need to reduce the running speed in tunnels means that the potential increase in operational energy consumption and emissions is not as high as earlier simulation work may suggest; however, such a reduction in running speed is likely to have wider commercial and socio-economic implications, which must also be taken in to account. 


\section{Acknowledgements}

This research was funded by the Engineering and Physical Sciences Research

605 Ove Arup \& Partners Ltd.

The authors would like to thank Arup for providing some of the data used in the paper, and for allowing the use of the RouteMaster simulation tool. This data are subject to a non-disclosure agreement.

Ademe, SNCF, RFF, 2009. 1st Bilan Carbone - global railway carbon footprint.

The Rhine-Rhone LGV serving Sustainable Europe. Technical Report.

Ahn, C., Xie, H., Lee, S., Abourizk, S., Mora, F.P.n., Ave, N.M., 2010. Carbon footprints analysis for Tunnel Construction Processes in the Preplanning Phase using Collaborative Simulation. Construction Research Congress 2010 615 , 1538-1546doi:10.1061/41109 (373) 154.

Allwood, J.M., Cullen, J.M., Carruth, M.A., 2012. Sustainable materials: with both eyes open. UIT Cambridge Cambridge.

AREMA, 2003. Chapter 2 - Railway Industry Overview, in: Practical Guide to Railway Engineering. chapter 2, pp. 33-57. URL: www.arema.org/ publications/pgre/Practical_Guide/PGChapter2.pdf.

Armstrong, J., Preston, J., 2010. Rail in the context of climate change: strengths, weaknesses, opportunities and threats, in: Proceedings from the 12th World Conference on Transport Research, Lisbon.

Arup, 2015. RouteMaster.

${ }_{625}$ Baron, T., Martinetti, G., Pepion, D., 2011. Carbon footprint of high speed rail. Technical Report. International Union of Railways. Paris. URL: http: //trid.trb.org/view . aspx?id=1134978.

Chang, B., Kendall, A., 2011. Life cycle greenhouse gas assessment of infrastructure construction for Californias high-speed rail system. 
Transportation Research Part D: Transport and Environment 16, 429-434. URL: http://linkinghub.elsevier.com/retrieve/pii/ S1361920911000484, doi:10.1016/j.trd.2011.04.004.

Chau, C., Soga, K., O'Riordan, N., Nicholson, D., 2009. Embodied Energy Evaluation for sections of the CTRL. URL: http://www. 
Technical Report. University of Bath. URL: http://www.bath.ac.uk/ mech-eng/sert/embodied/.

HS2 Ltd, 2009. HS2 Traction Energy Modelling. Technical

Report. URL: http://hs2.xplodelite.com/publications/ HS2-Traction-Energy-Modelling-49802.

HS2 Ltd, 2013. Impacts of tunnels in the UK (Non-technical summary).

Technical Report. URL: http://assets.hs2.org.uk/sites/default/ files/inserts/PR28_TunnellingReportNTS_0813.pdf.

ILF Inc. Consultants, 2009. Devils Slide Tunnels Project - New Austrian Tunneling Method. Technical Report. California Department of Transportation. URL: www.dot.ca.gov/dist4/dslide/images/ devilsslide_3updated.pdf.

Kiani, M., Ceney, H., Parry, T., 2008. Environmental life-cycle assessment of railway track beds. Proceedings of the ICE - Engineering Sustainability 161, 135-142. URL: http://www.icevirtuallibrary.com/content/article/ 10.1680/ensu.2008.161.2.135, doi:10.1680/ensu.2008.161.2.135.

Network Rail, 2009. Comparing environmental impact of conventional and high speed rail. Technical Report. URL: http://www . networkrail.co.uk/documents/Aboutus/NewLinesProgramme/5878_ Comparingenvironmentalimpactof conventionalandhighspeedrail.pdf.

Pritchard, J., 2015. Investigating the environmental sustainability of rail travel in comparison with other modes. Ph.D. thesis. University of Southampton.

Raghunathan, R.S., Kim, H.D., Setoguchi, T., 2002. Aerodynamics of high-speed railway train. volume 38. URL: http://linkinghub.elsevier. com/retrieve/pii/S0376042102000295, doi:10.1016/S0376-0421(02) 00029-5. 
Rail.One GmbH, 2011. Rheda 2000 Ballastless Track System. URL: http://www.railone.com/fileadmin/dateien/03_Broschueren/EN/ Rheda2000_EN_2011_ebook.pdf.

Rochard, B.P., Schmid, F., 2000. A review of methods to measure and calculate train resistances. Proceedings of the Institution of Mechanical Engineers, Part F: Journal of Rail and Rapid Transit 214, 185-199. URL: http:// pif.sagepub.com/lookup/doi/10.1243/0954409001531306, doi:10.1243/ 0954409001531306.

RSSB, 2007. Traction Energy Metrics. Technical Report. RSSB. URL: http://www.rssb.co.uk/SiteCollectionDocuments/pdf/reports/ research/T618_traction-energy-metrics_final.pdf.

RSSB, 2010a. Engineering Research into trains with lower mass in Britain: Quantification of benefit of train mass reduction. Technical Report. URL: http://www.rssb.co.uk/sitecollectiondocuments/pdf/reports/ research/T712_rpt_final.pdf.

RSSB, 2010b. Quantification of benefit of train mass reduction: E Annexes. Technical Report. RSSB. URL: http://www.rssb.co.uk/ sitecollectiondocuments/pdf/reports/research/T712_anxE.pdf.

Stimpson, J., 2011. Carbon footprints: lies, damned lies, and statistics? New Civil Engineer URL: http://www.nce.co.uk/opinion/jo-stimpson/ carbon-footprints-lies-damned-lies-and-statistics/8618424.blog.

SYSTRA, 2011. Carbon Impacts of HS2: Factors affecting carbon impacts of HSR. Technical Report. SYSTRA. URL: http://www.greengauge21.net/ wp-content/uploads/SYSTRA-Factors-affecting-HSR-carbon-impacts . pdf.

Transport for London, 2015. Facts \& Figures. URL: https: //tfl.gov.uk/corporate/about-tfl/what-we-do/london-underground/ facts-and-figures. 
Vergoulas, G., Lee, B., 2010. Crossrail carbon footprint study methodology and results. Technical Report. Crossrail Ltd.

Workman, R., Soga, K., 2004. The Embodied Energy of Tunnel Construction. Technical Report. University of Cambridge. Cambridge. 
Table 12: Estimated variation in embodied $\mathrm{CO}_{2}$ emissions with tunnel diameter for Crossrail

\begin{tabular}{|c|c|}
\hline Tunnel drameter [m] & $\begin{array}{r}\text { Increase in embodied } \mathrm{CO}_{2} \text { of materials } \\
\text { relative to } 6.2 \mathrm{~m} \text { tunnels [ } \mathrm{t} \text { per } \\
\text { route- } \mathrm{km} \text { ] }(\%)\end{array}$ \\
\hline 6.7 & $1,378(4)$ \\
\hline 7.2 & $2,761(17)$ \\
\hline 7.7 & $4,150(25)$ \\
\hline 8.2 & $5,544(33)$ \\
\hline 8.7 & $6,944(42)$ \\
\hline 9.2 & $8,350(50)$ \\
\hline 9.7 & $9,762(59)$ \\
\hline 10.2 & $11,179(67)$ \\
\hline 10.7 & $12,602(76)$ \\
\hline 11.2 & $14,030(84)$ \\
\hline 11.7 & $15,464(93)$ \\
\hline 12.2 & $16,904(102)$ \\
\hline 12.7 & $18,349(110)$ \\
\hline
\end{tabular}


Table 13: Estimated variation in operational energy consumption and $\mathrm{CO}_{2}$ emissions with tunnel diameter for Crossrail

Baseline work done (open-air $100 \mathrm{~km} / \mathrm{h}$

suburban profile with coasting)

[kWh per train-km]

Additional work done with a Tunnel

Factor of 1.1 [kWh per train-km]

Additional work done with a Tunnel

Factor of $2.2[\mathrm{kWh}$ per train-km]

Estimated energy saving of a Tunnel

Factor of 1.1 compared with a Tunnel

Factor of 2.2 [kWh per train-km]

Estimated reduction in $\mathrm{CO}_{2}$ emissions

$4.86 \times 10^{-4}$

[t per train-km]

Table 14: Estimated potential yearly reduction in $\mathrm{CO}_{2}$ emissions for Crossrail

Trains per hour

Operating hours per day

Trains per year

Reduction in $\mathrm{CO}_{2}$

emissions due to wider

tunnels (a reduced

Tunnel Factor of 1.1

compared with 2.2)

[t per $\mathrm{km}$ per year] 